\title{
Penurunan Tekanan Darah Pada Lansia Penderita Hipertensi Melalui Terapi Spiritual Emotional Freedom Technique (SEFT) dan Akupresur Titik Taichong
}

\author{
Roni Saputra $^{1^{*}}$, Budhi Mulyadi ${ }^{2}$, Mahathir $^{3}$ \\ ${ }^{1}$ Pasca Sarjana Keperawatan, Fakultas Keperawatan Universitas Andalas, Padang, Sumatera Barat, Indonesia \\ ${ }^{2}$ STIKes Indonesia, Padang, Sumatera Barat, Indonesia \\ ${ }^{3}$ Fakultas Keperawatan Universitas Andalas, Padang, Sumatera Barat, Indonesia \\ *Correspondence email: ronisaputra776@gmail.com
}

\begin{abstract}
Abstrak. Hipertensi merupakan salah satu penyakit yang banyak terjadi pada lansia dan akan berdampak pada kualitas dan kuantitas hidup lansia, untuk itu perlu penanganan lebih awal. Terapi SEFT dan Akupresur titik Taichong adalah terapi komplementer yang dapat menurunkan tekanan darah pada lansia tersebut. Penelitian ini bertujuan untuk menggambarkan ratarata tekanan darah sebelum dan sesudah dilakukan intervensi SEFT dan Akupresur titik Taichong. Desain dalam penelitian ini adalah deskriptif statistik. Sampel diambil dengan purposive sampling dan didapatkan 30 responden yang dibagi masing-masing 15 responden pada kelompok SEFT dan Kelompok Akupresur titik Taichong. Data dikumpulkan dengan lembar observasi dan dianalisa secara univariat. Hasil penelitian pada kelompok SEFT didapatkan nilai pre test tekanan darah sistol sebesar 164,00, diastole sebesar 94,67 dan tekanan darah post test tekanan darah sistol sebesar 149,67, diastol sebesar 90,00. Sedangkan pada kelompok Akupresur titik Taichong didapatkan nilai pre test tekanan darah sistol sebesar 153,33, diastole sebesar 93,33 dan tekanan darah post test tekanan darah sistol sebesar 142,67, diastol sebesar 88,67. Terapi SEFT dan Akupresur titik Taichong dapat menjadi alternatif dalam penurunan tekanan darah pada lansia.
\end{abstract}

Kata kunci: Akupresur; Hipertensi; Lansia; SEFT; Tekanan Darah

Abstract. Hypertension is a disease that often occurs in the elderly and will have an impact on the quality and quantity of life of the elderly, so it needs early treatment. SEFT therapy and taichong point acupressure are complementary therapies that can lower blood pressure in the elderly. The design in this research is descriptive statistics. The sample was taken by purposive sampling and obtained 30 respondents who were divided into 15 respondents each in the SEFT group and the taichong point acupressure group. Data were collected using observation sheets and analyzed univariately. The results of the research in the SEFT group showed that the pre-test systolic blood pressure was 164.00, the diastole was 94.67 and the post-test systolic blood pressure was 149.67, the diastole was 90.00. Whereas in the taichong point acupressure group, the pre-test systolic blood pressure was 153.33, the diastole was 93.33 and the systolic blood pressure post-test was 142.67, the diastole was 88.67. SEFT therapy and taichong point acupressure can be an alternative in reducing blood pressure in the elderly.

Keywords: Acupresure; Blood Pressure; Elderly; Hypertension; SEFT

\section{PENDAHULUAN}

Populasi lansia diperkirakan terus mengalami peningkatan, saat ini kita mulai memasuki periode aging population. Indonesia memiliki jumlah lansia pada tahun 2019 sebanyak 25,9 juta jiwa $(9,7 \%)$, dan diperkirakan akan terus meningkat dimana tahun 2035 menjadi 48,2 juta jiwa (15,77\%) (Kemenkes, 2019). Suardiman (2011) mengatakan semakin meningkatnya jumlah penduduk usia lanjut akan berpengaruh terhadap berbagai aspek kehidupan berhubungan dengan penurunan kondisi fisik, psikis dan sosial. Penurunan kondisi fisik akan berdampak pada kondisi yang rawan terhadap berbagai macam gangguan penyakit. Menurut data telah menunjukkan peningkatan prevalensi hipertensi pada lanjut usia. Resiko penyakit arteri koroner, stroke, penyakit jantung kongestif, insufsiensi ginjal kronis, dan demensia juga meningkat pada lansia hipertensi (Lionakis dkk, 2012).

Hipertensi adalah penyakit yang banyak terjadi pada dan juga dapat menimbulkan berbagai komplikasi.
Menurut (Dzau and Balatbat, 2019) komplikasi hipertensi yaitu stroke trombolitik dan hemoragik, retinopati, Infark miokard akut, gagal jantung, proteinuria, gagal ginjal, penyakit pembuluh darah aterosklerotik termasuk stenosis dan aneurisma.

Melihat dampak dan komplikasi yang ditimbulkan hipertensi, pemerintah telah melakukan upaya dalam pencegahan dan pengendalian hipertensi diantaranya adalah meningkatkan promosi kesehatan melalui Komunikasi Infromasi Edukasi (KIE) dalam pengendalian hipertensi seperti perilaku CERDIK dan PATUH, meningkatkan pencegahan dan pengendalian hipertensi berbasis masyarakat dengan self awareness melalui pengukuran tekanan darah selain itu pemerintah juga telah melakukan upaya seperti meningkatkan akses ke Fasilitas Kesehatan Tingkat Pertama (FKTP), optimalisasi sistem rujukan, dan peningkatan mutu pelayanan, salah satu upaya pencegahan komplikasi hipertensi khususnya penyakit jantung dan pembuluh darah di FKTP melalui Pelayanan Terpadu (PANDU 
PTM 5). Pemberdayaan masyarakat dalam deteksi dini dan monitoring faktor risiko dini dan monitoring peningkatan faktor resiko hipertensi melalui Posbindu PTM dan Posbindu Lansia (Kemenkes, 2019).

Hipertensi pada lansia dapat dimanajemen secara farmakologis maupun secara non farmakologis. Penelitian dari Ainurrafiq dkk (2019) mengatasi hipertensi dapat dilakukan berbagai upaya yaitu pemberian terapi non farmakologis berupa: modifikasi gaya hidup, mengurangi berat badan, pembatasan asupan natrium, modifikasi diet rendah lemak, pembatasan alkohol, pembatasan kafein, menghentikan kebiasaan merokok dan kendalikan stres.

Penelitian yang dilakukan oleh Seke dkk (2016) menyebutkan ada hubungan antara kejadian stres dengan hipertensi pada lansia. Menurut Jadhav et al., (2014) dari 213 kasus hipertensi yang diteliti $(5,92 \%)$ ketika stres meningkat maka resiko hipertensi meningkat. Hubungan yang signifikan secara statistik ditemukan antara stres mental dan hipertensi terutama pada laki-laki. Stres mental jelas merupakan salah satu faktor resiko hipertensi. sehingga diperlukan tindakan dan latihan penghilang stres seperti tehnik relaksasi.

Tekhnik relaksasi merupakan salah satu teknik pengolahan diri yang didasarkan pada cara kerja sistem saraf simpatis dan parasimpatis. Relaksasi ini mampu menghambat stres atau ketegangan jiwa yang dialami seseorang sehingga tekanan darah tidak meninggi atau menurun, sehingga relaksasi akan membuat kondisi seseorang dalam keadaan rileks atau tenang, dalam mekanisme autoregulasi, relaksasi dapat menurunkan tekanan darah dengan cara penurunan denyut jantung dan Total Peripheral Resistance (Corwin, 2009).

Rofacky \& Aini (2015) mengatakan SEFT merupakan salah satu terapi relaksasi yang bisa dijadikan alternatif untuk menangani hipertensi. Penelitian yang dilakukan oleh Purwanto \& Sakinah (2014) tentang efektifitas terapi SEFT dalam menurunkan hipertensi diperoleh hasil bahwa terapi SEFT efektif untuk menurunkan hipertensi. Akupresur adalah tindakan yang berdasarkan pada pengobatan tradisional Cina serta bentuk lain akupunktur non invasif dengan merangsang akupoin dengan menggunakan jari, tangan atau siku untuk memudahkan aliran energi $q i$ (energi vital) sepanjang meridian (Yeung et al., 2018). Akupresur disebut juga sebagai terapi totok/tusuk jari sebagai suatu bentuk fisioterapi dengan memberikan pijatan dan stimulus pada titik-titik tertentu atau accupoint pada tubuh (Setyowati, 2018).

Menurut penelitian yang dilakukan Lin et al (2016). Dengan memberikan intervensi akupresur taichong accupoint selama 15 menit pada 80 pasien hipertensi dengan cara kelompok dibagi menjadi dua yaitu kelompok eksprimen $(n=40)$ pada taichong accupoint di daerah antara metatarsal pertama dan kedua. Sedang kelompok kontrol $(\mathrm{n}=40)$ pada sham accupoint (placebo) masing-masing menggunakan obat hipertensi dengan rerata tekanan darah menurun pada kelompok eksprimen $(\mathrm{P}<0.05)$, sedangkan kelompok kontrol tidak ada perubahan signifikan.

\section{METODE}

Penelitian ini adalah penelitian deskriptif kuantitatif. Data dikumpulkan dan dicatat pada lembar observasi baik tekanan darah sistol maupun tekanan darah diastol kelompok SEFT dan kelompok Akupresur titik Taichong. Populasi dalam penelitian ini adalah pasien lansia hipertensi di wilayah kerja puskesmas. Sampel dipilih menggunakan purposive sampling dengan jumlah sampel 30 responden dan dibagi menjadi 15 responden untuk kelompok SEFT dan 15 responden untuk kelompok Akupresur titik Taichong. Penelitian ini juga telah lulus uji etik dengan nomor No.170/KEP/FK/2020.

\section{HASIL DAN PEMBAHASAN}

Setelah dilakukan penelitian, tekanan darah pada kelompok SEFT dan kelompok Akupresur titik Taichong adalah sebagai berikut:

Tabel 1. Tekanan darah lansia dengan hipertensi sebelum dan sesudah diberikan terapi SEFT

\begin{tabular}{|c|c|c|c|c|c|}
\hline Var & & Mean & Beda Mean & SD & $\mathbf{N}$ \\
\hline Intervensi SEFT & $\begin{array}{l}\text { Pre test } \\
\text { Post test }\end{array}$ & $\begin{array}{l}164,00 \\
149,67\end{array}$ & 14,33 & $\begin{array}{l}14,04 \\
15,17\end{array}$ & 15 \\
\hline
\end{tabular}

Sumber: Data diolah

Pada tabel 1 terlihat adanya penurunan rata-rata tekanan darah pada lansia dengan hipertensi. Hal tersebut terlihat pada rata-rata pre test tekanan darah lansia sebesar $164,00 \mathrm{mmHg}$ dan pada rata-rata post test tekanan darah lansia sebesar 149,67 mmHg. Berdasarkan hasil tersebut dapat disimpulkan bahwa adanya penurunan tekanan rata-rata tekanan darah sebesar 14,33 .

Tabel 2. Tekanan darah lansia dengan hipertensi sebelum dan sesudah diberikan terapi Akupresur Titik Taichong

\begin{tabular}{cccccc}
\hline Variabel & & Mean & Beda Mean & SD & N \\
\hline Intervensi Akupresur & Pre test & 153,33 & \multirow{2}{*}{10,66} & 11,12 & 15 \\
titik Taichong & Post test & 142,67 & & 16,67 & \multirow{2}{*}{. }
\end{tabular}

Sumber: Data diolah 
Pada tabel 2 terlihat adanya penurunan rata-rata tekanan darah pada lansia dengan hipertensi. Hal tersebut terlihat pada rata-rata pre test tekanan darah lansia sebesar 153,33 $\mathrm{mmHg}$ dan pada rata-rata post test tekanan darah lansia sebesar 142,67 mmHg. Berdasarkan hasil tersebut dapat disimpulkan bahwa adanya penurunan tekanan rata-rata tekanan darah sebesar 10,66 $\mathrm{mmHg}$.

\section{Pembahasan}

Hipertensi merupakan penyebab paling umum terjadinya penyakit kardiovaskular dan merupakan masalah utama di negara maju maupun berkembang (WHO, 2019). Hasil dari penelitian menunjukkan ratarata tekanan darah baik pada kelompok SEFT maupun kelompok Akupresur titik Taichong mengalami penurunan setelah dilakukan intervensi. Namun, penurunan tekanan darah pada kelompok SEFT lebih besar dibandingkan dengan kelompok Akupresur titik Taichong.

Teknik SEFT menggunakan unsur spiritual, cara yang digunakan lebih aman, lebih mudah, lebih cepat dan lebih sederhana, karena SEFT hanya menggunakan ketukan tangan (tapping). Teknik ini menggabungkan sistem energy tubuh (energy medicine) dan terapi spiritual yang digunakan merupakan salah satu teknik terapi untuk mengatasi masalah emosional dan fisik yaitu dengan melakukan ketukan ringan (tapping) pada titik syaraf (meridian tubuh) (Zainnuddin, 2009). Penelitian yang dilakukan oleh Purwanto \& Sakinah (2014) tentang efektifitas terapi SEFT dalam menurunkan hipertensi diperoleh nilai rata-rata sistol pre test sebesar $154 \mathrm{mmHg}$ dan post test sebesar $138 \mathrm{mmHg}$ dengan perbedaan $16 \mathrm{mmHg}$, sedangkan nilai rata-rata diastol pre test sebesar $93 \mathrm{mmHg}$ dan post test sebesar $88 \mathrm{mmHg}$ dengan perbedaan $5 \mathrm{mmHg}$, sehingga disimpulkan bahwa terapi SEFT efektif untuk menurunkan hipertensi.

Sonhaji dan Lekatompessy (2019) mengatakan terapi SEFT lebih efektif dalam menurunkan tekanan darah pada lansia penderita hipertensi dibandingkan intervensi menyanyi, baik tekanan darah sistol maupun tekanan darah diastol. Terapi SEFT juga dapat menurunkan tekanan darah pada ibu hamil, penelitian yang dilakukan Permatasari (2020) menggunakan terapi SEFT dengan durasi 30 menit dan dilakukan selama 14 hari dapat menurunkan rata-rata darah, dimana nilai tekanan sistol menurun sebesar $12 \mathrm{mmHg}$ dan tekanan darah diastol menurun sebesar $12,8 \mathrm{mmHg}$ lebih tinggi dibandingkan yang tidak diberikan SEFT.

Sedangkan Akupresur adalah tindakan yang berdasarkan pada pengobatan tradisional Cina yang merangsang akupoin dengan menggunakan jari, tangan atau siku untuk memudahkan aliran energi vital sepanjang meridian (Yeung dkk, 2018). Penelitian yang dilakukan Lin dkk (2016), dengan memberikan intervensi akupresur taichong accupoint selama 15 menit pada 80 pasien hipertensi didapatkan nilai tekanan darah sistol pre test sebesar $165,0 \mathrm{mmHg}$ dan menurun pada post test sebesar $142,9 \mathrm{mmHg}$, kemudian pada nilai diastole pre test sebesar 96,3 menurun pada post test sebesar 88,6 mmHg, sehingga dapat disimpulkan bahwa akupresur pada titik Taichong dapat menurunkan tekanan darah pada pasien hipertensi dan disarankan agar dapat dimasukkan dalam rencana asuhan keperawatan untuk penderita hipertensi.

Dermawan dkk (2019) juga mendapatkan hasil yang sama pada penelitianya, bahwa akupresur secara mandiri yang bisa dilakukan sendiri dan keluarga secara signifikan menurunkan tekanan darah sistolik sebesar $18,05 \mathrm{mmHg}$, penekanan pada titik-titik tertentu adalah salah satu imtervensi nonfarmakologis yang efisien dan aman karena bukan tindakan invasif. Penelitian dari Zheng dkk (2014) mengatakan Akupresur tidak hanya dapat menurunkan tekanan darah sistolik tetapi juga secara efektif dapat meningkatkan kualitas tidur pada pasien dewasa dan lansia dengan masalah hipertensi.

\section{SIMPULAN}

Terapi SEFT dan Akupresur titik Taichong dapat menurunkan tekanan darah pada lansia dengan hipertensi. Sehingga, Terapi SEFT dan Akupresur titik Taichong dapat digunakan oleh pihak puskesmas sebagai terapi komplementer dan menjadi alternatif dalam penurunan tekanan darah pada lansia dengan hipertensi.

\section{DAFTAR PUSTAKA}

Ainurrafiq, A., Risnah, R. and Ulfa Azhar, M. (2019) 'Terapi Non Farmakologi dalam Pengendalian Tekanan Darah Pada Pasien Hipertensi: Systematic Review', MPPKI (Media Publikasi Promosi Kesehatan Indonesia): The Indonesian Journal of Health Promotion, 2(3), pp. 192-199. doi: 10.31934/mppki.v2i3.806.

Corwin, E. J. (2009) Buku Saku Patofisiologi. Jakarta: Penerbit Buku Kedokteran EGC.

Dermawan, A. C., Setiawati, S. and Maryam, R. S. (2019) 'Self-Acupressure To Lower Blood Pressure on Older Adults With Hypertension', Jurnal Riset Kesehatan, 8(2), p. 1. doi: 10.31983/jrk.v8i2.3879.

Dzau, V. J. and Balatbat, C. A. (2019) 'Future of Hypertension', Hypertension, 74(3), pp. 450-457. doi: 10.1161/hypertensionaha.119.13437.

Kemenkes (2019) Hipertensi The Silent Killer.

Lin, G. H. et al. (2016) 'Effectiveness of Acupressure on the Taichong Acupoint in Lowering Blood Pressure in Patients with Hypertension: A Randomized Clinical Trial', Evidence-based Complementary and Alternative Medicine, 2016, p. 9. doi: $10.1155 / 2016 / 1549658$.

Lionakis, N. et al. (2012) 'Hypertension in the elderly', 
4(5), pp. 135-147. doi: 10.4330/wjc.v4.i5.135.

Permatasari, A. S. et al. (2020) 'Spiritual Emotional Freedom Technique ( SEFT) Intervention on Blood Pressure among Pregnancy with Hypertension', International Journal of Nursing and Health Services (IJNHS), 3(3), pp. 402-410. doi: 10.35654/ijnhs.v3i3.233.

Purwanto, E. and Sakinah, T. (2014) 'Efektivitas Terapi SEFT Dalam Menurunkan Hipertensi ( The Effect of SEFT Therapy to Decrease Hypertension )', 1(2), pp. 97-102. doi: 10.26699/jnk.v1i2.ART.p0.

Rofacky, H. and Aini, F. (2015) 'Pengaruh Terapi Spiritual Emotional Freedom Technique (SEFT) terhadap Penurunan Tekanan Darah Penderita Hipertensi', Jurnal Keperawatan Soedirman, 2(1), pp. 17-23. Available at: http://jks.fikes.unsoed.ac.id/index.php/jks/article/v iew/185/86gmbran.

Seke, P. A., Bidjuni, H. J. and Lolong, J. (2016) 'Hubungan Kejadian Stres Dengan Penyakit Hipertensi Pada Lansia Di Balai Penyantunan Lanjut Usia Senjah Cerah Kecamatan Mapanget Kota Manado', Jurnal Keperawatan, 4(August), pp. 1-5.

Setyowati, H. (2018) Akupresur untuk kesehatan wanita berbasis hasil penelitian. Semarang: Unimma Press.

Sonhaji, S. and Lekatompessy, R. (2019) 'Efektifitas Spiritual Emotional Freedom Technique (SEFT) dan menyanyi terhadap tekanan darah lansia di rumpelsos pucang gading semarang', Health Sciences and Pharmacy Journal, 3(1), p. 14. doi: 10.32504/hspj.v3i1.93.

Suardiman, S. P. (2011) Psikologi Usia Lanjut. 1st edn. Yogyakarta: Gadjah Mada University Press.

WHO (2019) Hypertension: Act Now.

Yeung, W.-F. et al. (2018) 'Self-administered acupressure for insomnia disorder: A pilot randomized controlled trial', European Sleep Research Society, 27, pp. 220-231. doi: $10.1111 /$ jsr. 12597 .

Zainnuddin, A. F. (2009) Spritual Emotional Freedom Technique (SEFT) for Healing, success, hapipiness, greatness. Jakarta Timur: Afzan.

Zheng, L. W. et al. (2014) 'Effect of acupressure on sleep quality of middle-aged and elderly patients with hypertension', International Journal of Nursing Sciences. Elsevier Ltd, 1(4), pp. 334-338. doi: 10.1016/j.ijnss.2014.10.012. 